\title{
Purine Metabolism During Strenuous Muscular Exercise in Man
}

\author{
John R. Sutton, Cornelius J. Toews, Graham R. Ward, and Irving H. Fox
}

\begin{abstract}
This study was designed to examine the influence of exercise on purine metabolism in man. In 15 men. the plasma uric acid concentration increased from 6.9 to $8.5 \mathrm{mg} / \mathrm{dl}$ following a $5000-\mathrm{m}$ race and from 6.2 to $7.9 \mathrm{mg} / \mathrm{dl}$ in $11 \mathrm{men}$ following a $42-\mathrm{km}$ marathon. During a progressive exercise test on a cycle ergometer, the plasma uric acid concentration did not change significantly in 11 subjects. However, the plasma oxypurines increased from $19 \mu M$ at rest to $50 \mu \mathrm{M}$ at exhaustion and the urinary excretion of oxypurines increased from 140 to $400 \mu \mathrm{mol} / \mathrm{g}$ creatinine. Intracellular ATP decreased from 5.17 to $2.91 \mu \mathrm{mol} / \mathrm{g}$ and ADP and AMP increased from 0.85 to 1.29 and from 0.12 to $0.15 \mu \mathrm{mol} / \mathrm{g}$ wet weight, respectively. These observations suggest that there is an accelerated degradation of purine nucleotides to the precursors of uric acid in skeletal muscle during vigorous exercise.
\end{abstract}

$\mathbf{T}^{0}$ ELUCIDATE the biochemical basis for the regulation of metabolic pathways in normal and disease states in man, it is often necessary to study a model manipulated to its extremes of function. The understanding of human purine metabolism has developed in this manner. The major milestones were achieved by the discovery of inherited disorders and drugs that modify normal biochemical control mechanisms. ${ }^{1-3}$

As strenuous exercise increases the plasma uric acid $^{4-9}$ and plasma oxypurines ${ }^{10}$ concentrations, it may also provide a physiologic model to study the normal regulation of purine metabolism.

The present study was performed to examine the regulation of purine metabolism during exercise using the xanthine oxidase inhibitor, allopurinol. We demonstrate that exercise alters body

From the Departments of Medicine and Biochemistry, McMaster University. Hamilton, Ontario, Canada, and the University of Michigan. Ann Arbor. Mich.

Received for publication May 2, 1979.

Supported in part by grants from the Medical Research Council of Canada, the Ontario Heart Foundation, and USPHS Grants AM 19674 and $5 M O 1$ RR-42-14.

Address reprint requests to Dr. J. R. Sutton. Room 3 U26, McMaster University Medical Centre, 1200 Main Street West, Hamilton, Ontario, Canada L8S 4J9.

(c) 1980 by Grune \& Stratton, Inc.

$0026-0495 / 80 / 2903-0007 \$ 01.00 / 0$ purine metabolism by increasing the rate of oxypurine formation. The source of the oxypurines is not clear, but arguments are presented which suggest that they may be derived from muscle adenine nucleotides.

\section{MATERIALS AND METHODS}

\section{Exercise Procedures}

Four studies were conducted on normal, healthy men to whom the nature and risks of the experiments were explained and who then gave informed consent. Studies 1 and 2 were conducted during athletic competition, whereas studies 3 and 4 were conducted in a laboratory, using a cycle ergometer.

Study 1. Venous blood was collected before and immediately after the completion of a 5000 meter race in a veterans athletic meet. Samples were obtained in 15 healthy men whose mean age was 49 years $(36-67 \mathrm{yr}$ ).

Study 2. In 11 subjects, mean age 32 years $(20-67 \mathrm{yr})$ venous blood was obtained just prior to and within three minutes of completing a $42 \mathrm{~km}$ marathon race.

Study 3. A maximum progressive cycle ergometer test ${ }^{1}$ was performed in 11 normal men, mean age 30 years (22-42 yr). Venous blood samples were obtained at rest, following a 12-hour overnight fast, at exhaustion, and at 30 minutes following exercise. The exercise was started at $100 \mathrm{kpm} / \mathrm{min}$ and was increased by $100 \mathrm{kpm} / \mathrm{min}$ each minute until exhaustion. The heart rate was monitored continuously by a $\mathrm{V}_{3}$ bipolar electrode and recorded at minute intervals

Study 4. The subjects in Study 3 were restudied as previously outlined, except that the subjects took allopurinol orally, $200 \mathrm{mg}$ every 6 hours for two days. The last dose of allopurinol was taken two hours prior to the exercise study.

In all the studies, the venous blood was collected in heparinized tubes and stored on ice until centrifuged. The plasma was stored at $-20^{\circ} \mathrm{C}$ until analyzed. In studies 3 and 4 , where urine samples were analyzed, collections were made over a 45-minute period before exercise and over a further 30 minutes, which included the exercise period. The samples were stored at $-20^{\circ} \mathrm{C}$ until analyzed. In eight subjects, needle muscle biopsies were obtained from the vastus lateralis group at rest and at exhaustion. ${ }^{12}$ The biopsies were frozen in liquid nitrogen within two seconds of sampling and stored in liquid nitrogen until a nalyzed. Muscle biopsies were only taken in the control study, ie without allopurinol.

\section{Analytical Techniques}

Uricase, xanthine oxidase, and purine nucleoside phosphorylase in $3.0 \mathrm{M}$ ammonium sulfate were obtained from Sigma Chemical Co., St. Louis, Mo. All chemicals utilized were of the highest quality available commercially. Uric acid was determined by the uricase method. ${ }^{13}$ Urine creatinine was determined as previously described ${ }^{14}$ and the urine oxypurines were determined using enzymatic spectrophotometric methods. ${ }^{15}$ The relative quantity of urine hypoxan- 
Table 1. Biochemical Effects of Races

\begin{tabular}{|c|c|c|c|c|c|c|c|c|c|c|c|c|c|}
\hline & $\begin{array}{l}\mathrm{Na}^{+} \\
\{\mathrm{mM}\}\end{array}$ & $\begin{array}{l}\mathrm{K} \\
(\mathrm{mM})\end{array}$ & $\frac{\mathrm{Cl}}{\langle\mathrm{mM}\rangle}$ & $\begin{array}{r}\mathrm{HCO}_{3} \\
(\mathrm{mM})\end{array}$ & $\begin{array}{l}\text { Urea } \\
(\mathrm{mg} / \mathrm{dl})\end{array}$ & $\begin{array}{l}\text { Uric } \\
\text { Acid } \\
\text { (mg/dd) }\end{array}$ & $\begin{array}{l}\text { Creat- } \\
\text { inine } \\
\{\mathrm{mg} / \mathrm{d} \mid\}\end{array}$ & $\begin{array}{l}\mathrm{PO}_{4} \\
(\mathrm{mg} / \mathrm{dl})\end{array}$ & $\begin{array}{l}\mathrm{Ca}^{++} \\
(\mathrm{mg} / \mathrm{dl})\end{array}$ & $\begin{array}{l}\mathrm{Mg}^{++} \\
(\mathrm{mg} / \mathrm{dl})\end{array}$ & $\begin{array}{l}\text { Alburmin } \\
\text { (g/d) }\end{array}$ & $\begin{array}{c}\text { SGOT } \\
(\mu \mathrm{U} / \mathrm{ml} / \mathrm{min})\end{array}$ & $\begin{array}{c}C P K \\
\{\mu U / \mathrm{ml} / \mathrm{m} n \mathrm{n}\}\end{array}$ \\
\hline \multicolumn{14}{|c|}{$\begin{array}{l}5000 \text { Meter Race } \\
\quad(n=15)\end{array}$} \\
\hline Before: Mean & 145 & 4.1 & 101 & 29 & 27.2 & 6.9 & 1.0 & 3.2 & - & - & 5.4 & - & - \\
\hline t SEM & 1 & 0.1 & 1 & 1 & 1 & 0.2 & 0.0 & 0.1 & - & - & 0.1 & - & - \\
\hline After: Mean & $141+$ & $3.9 \dagger$ & $103 \S$ & $14 \S$ & $27.4^{*}$ & $8.4 \S$ & $1.5 \S$ & $4.8 \S$ & - & - & $5.4^{*}$ & - & - \\
\hline+ SEM & 1 & 0.1 & 1 & 1 & 1 & 0.2 & 0.1 & 0.2 & - & - & 0.1 & $\infty$ & $\cdots$ \\
\hline \multicolumn{14}{|c|}{$\begin{array}{l}\text { Marathon Race } \\
\qquad n=11\}\end{array}$} \\
\hline Before: Mean & 143.4 & 4.0 & 102.4 & 28.2 & 33.4 & 6.2 & 1.0 & 4.1 & 10.0 & 2.0 & 5.5 & 9.8 & 72 \\
\hline \pm SEM & 0.8 & 0.1 & 0.8 & 0.6 & 1.7 & 0.4 & 0.04 & 0.4 & 0.1 & 0.1 & 0.1 & 0.8 & 15 \\
\hline After: Mean & $147.6 \S$ & $4.4 \S$ & $102.4^{*}$ & $26.4 \ddagger$ & $46.6 \S$ & $7.9 \S$ & $1.2 \dagger$ & $4.5^{*}$ & $9.6 \S$ & $2.0^{*}$ & $6.2 \S$ & $14.9 \S$ & $195 \S$ \\
\hline \pm SEM & 0.9 & 0.1 & 1.0 & 0.5 & 3.4 & 0.3 & 0.1 & 0.2 & 0.1 & 0.1 & 0.1 & 1.3 & 44 \\
\hline
\end{tabular}

Significance of $t$ test: $*$, not significant: $\uparrow, p<0.05 ; \ddagger \rho<0.025 ; \S p<0.01$.

thine and xanthine were determined by differential spectroscopy (H. Fraser and I.H. Fox, unpublished method). Plasma oxypurine concentrations were determined by using a modification of the urinary oxypurine method. ${ }^{15}$ Plasma protein was precipitated with one volume of $3.0 \mathrm{M}$ perchloric acid. The protein was removed by centrifugation and the supernatant brought to $\mathrm{pH} 4$ to 5 with $4.0 \mathrm{~N} \mathrm{KOH}$. The neutralized plasma protein-free extract was incubated in $0.07 \mathrm{M}$ sodium pyrophosphate, $\mathrm{pH} 8.0$ with uricase $(2.4 \mathrm{IU} / \mathrm{ml}$ buffer $)$ for 18 hours. The reaction was stopped by the addition of 0.25 $\mathrm{ml}$ of $4.0 \mathrm{~N} \mathrm{NaOH}$. Finally. $\mathrm{HCl}$ was added to bring the $\mathrm{pH}$ to 8.0 and the oxypurines were assayed as outlined previously. ${ }^{16}$ The assay was linear up to $90 \mu M$ and recoveries of $83 \%$ were obtained when known quantities of hypoxanthine were added.

Urine inosine concentration was determined by a modification of the method outlined for plasma oxypurines. The inosine was converted to uric acid by incubating the perchloric-neutralized extract with 0.6 IU of nucleoside phosphorylase and 0.12 IU of xanthine oxidase in $50 \mathrm{~m} M$ sodium phosphate buffer, $\mathrm{pH} 8.0$ for 30 minutes. The uric acid concentration was then determined using the uricase method $^{15}$ with appropriate controls to determine the uric acid concentration before determination of the inosine concentration.

Skeletal muscle ATP, ADP, and AMP were measured using enzymatic fluorometric methods. ${ }^{17}$ Plasma lactate was measured similarly. ${ }^{17}$ Other biochemical variables were measured using standard techniques (Table 1).

\section{RESULTS}

\section{Studies 1 and 2}

The serum uric acid concentration increased from $6.9 \mathrm{mg} / \mathrm{dl}$ at rest to $8.4 \mathrm{mg} / \mathrm{dl}$ following the 5000 meter race $(p<0.01)$ and from $6.2 \mathrm{mg} / \mathrm{dl}$ to $7.9 \mathrm{mg} / \mathrm{dl}$ during the marathon $(p<0.01$, Table 1). The basis for the elevated serum uric acid was unclear from these studies. There were other changes in the plasma biochemical data during the races, but none of these could directly provide a mechanism for the observed increase in the plasma uric acid concentration following the races (Table 1).

\section{Studies 3 and 4}

There was no difference in exercise performance with or without allopurinol. The values for maximum heart rate was 184 on each occasion, the maximum power output was 1590 and $1580 \mathrm{kpm}$ and the plasma lactate values at exhaustion were 6.7 and $6.6 \mathrm{mM}$ respectively (Table 2).

Uric acid production was assessed by measuring changes in plasma and urine uric acid, oxypurines, and inosine concentrations. An increase in the accumulation of these metabolites was interpreted as an acceleration of the pathways responsible for the formation of uric acid.

During exercise, the following alterations were observed: (1) the mean plasma uric acid did not change (Table 2); (2) the urine uric acid diminished from a mean value of 0.45 to 0.36 $\mathrm{mg} / \mathrm{mg}$ creatinine (Table 3 ), a $20 \%$ decrease which was not statistically significant, and the uric acid clearances were similarly reduced; (3) the mean plasma oxypurine concentration increased from a mean value of $19 \mu M$ to $35 \mu M$ $(p<0.10)$ immediately after exercise and then to $50 \mu M(p<0.01)$ after the rest period (Table 2 ); (4) the mean urinary oxypurine (Table 3 ) increased from 0.14 to $0.40 \mu \mathrm{mol} / \mathrm{mg}$ creatinine, a $195 \%$ increase $(p<0.02)$, which was completely related to an increase of hypoxanthine excretion and accompanied by a $73 \%$ increase in the ratio of the oxypurine clearance 
Table 2. Effect of Allopurinol on Work Capacity, Maximum Heart Rate, Plasma Lactate,

Plasma Uric Acid and Plasma Oxypurine Concentrations

\begin{tabular}{|c|c|c|c|c|c|c|}
\hline & \multicolumn{3}{|c|}{ Control } & \multicolumn{3}{|c|}{ Allopurinol } \\
\hline & Rest & Exhaustion & Postexercise & Rest & Exhaustion & Postexercise \\
\hline \multicolumn{7}{|c|}{ Maximum Power Output } \\
\hline$(\mathrm{kpm} / \mathrm{min})$ & - & $1590 \pm 100$ & - & - & $1578 \pm 111$ & - \\
\hline \multicolumn{7}{|l|}{ Maximum Heart Rate } \\
\hline (beats $/ \mathrm{min}$ ) & - & $184 \pm 6$ & - & - & $184 \pm 5$ & - \\
\hline \multicolumn{7}{|l|}{ Plasma Lactate } \\
\hline$(\mathrm{m} M)$ & $0.88 \pm 0.8$ & $6.6 \pm 0.8$ & - & $1.2 \pm 0.2$ & $6.7 \pm 0.4$ & - \\
\hline \multicolumn{7}{|l|}{ Plasma Uric Acid } \\
\hline$(\mathrm{mg} / \mathrm{dl})$ & $6.2 \pm 0.3$ & $6.2 \pm 0.2$ & $6.3 \pm 0.3$ & $3.7 \pm 0.2$ & $3.8 \pm 0.2$ & $3.7 \pm 0.3$ \\
\hline \multicolumn{7}{|l|}{ Plasma Oxypurines } \\
\hline$(\mu$ mole $)(n=7)$ & $19.0 \pm 2.0$ & $35.3 \pm 7.0$ & $50.4 \pm 4.0$ & $18.3 \pm 4.0$ & $59.0 \pm 9.0$ & $82.7 \pm 10.0$ \\
\hline
\end{tabular}

to the creatinine clearance; (5) no adenosine was detected in the urine, but an increase in urinary inosine was noted in 4 of 5 subjects following exercise (Table 4); and (6) the mean serum creatinine was $0.83 \pm 0.03$ (SEM) before and $0.93 \pm 0.02(\mathrm{SEM}) \mathrm{mg} / \mathrm{dl}$ during the exercise period.

Allopurinol was used to block xanthine oxidase in an effort to diminish exercise effects on uric acid and magnify changes in oxypurines. The latter was only partially successful since only minimal, if any, changes were observed in plasma uric acid during the cycle ergometer exercise test, although basal levels decreased from $6.2 \pm 0.3$ to $3.7 \pm 0.2 \mathrm{mg} / \mathrm{dl}(p<0.01)$, During the exercise with allopurinol, the following were observed: (1) the mean plasma uric acid of $3.7 \mathrm{mg} / \mathrm{dl}$ did not change (Table 2); (2) the mean urinary uric acid decreased from 0.20 to $0.18 \mathrm{mg} / \mathrm{mg}$ creatinine (Table 3 ), a $9 \%$ diminution which was not statistically significant, and the uric acid clearance was similarly reduced; (3) the mean plasma oxypurine increased from $18 \mu M$ to $59 \mu M(p<0.02)$ immediately after exercise and then to $83 \mu M(p<0.01)$ after the recovery period (Table 2); and (4) the mean urinary oxypurine increased from 0.95 to 1.01 $\mu \mathrm{mol} / \mathrm{mg}$ creatinine (Table 3 ), an insignificant change. Estimates of the ratio of the oxypurine clearance to the creatinine clearance indicated a diminution of $64 \%$ during exercise, suggesting that the lack of an increase in urine oxypurines was related to a decreased oxypurine clearance.

These data demonstrate an increased production of uric acid precursors which could eventually lead to a rise in uric acid synthesis. A potential source for these increased purine catabolic intermediates was sought in the adenine nucleotide content of the exercising skeletal muscle (Table 5). Exercise decreased the muscle ATP concentration from 5.17 to $2.91 \mu \mathrm{mol} / \mathrm{g}$ wet weight $(p<0.001)$ and ADP increased from 0.85 to $1.29 \mu \mathrm{mol} / \mathrm{g}(p<0.01)$, while AMP concentrations did not change. Total adenine nucleotides decreased from a mean value of 6.14 to $4.35 \mu \mathrm{mol} / \mathrm{g}$ wet weight $(p<0.01)$.

\section{DISCUSSION}

Vigorous muscular exercise has been previously recognized as a cause of hyperuricemia. ${ }^{4-9}$ Although the exact basis for this elevation of the serum uric acid has remained unclear, it appears that more severe and prolonged forms of exertion are related to greater increases in this

Table 3. Effect of Exercise on Urinary Uric Acid and Oxypurines

\begin{tabular}{|c|c|c|c|c|}
\hline & \multicolumn{2}{|c|}{ Control } & \multicolumn{2}{|c|}{ Allopurinol } \\
\hline & Rest & Exercise & Rest & Exercise \\
\hline \multicolumn{5}{|l|}{ Urinary Uric Acid } \\
\hline ( $\mathrm{mg} / \mathrm{mg}$ creatinine) & $0.45 \pm 0.09$ & $0.36 \pm 0.12$ & $0.20 \pm 0.05$ & $0.18 \pm 0.05$ \\
\hline ( $\mu$ mole $/ \mathrm{mg})$ & $(2.81 \pm 0.56)$ & $\{2.25 \pm 0.75\rangle$ & $(1.25 \pm 0.31)$ & $(1.13 \pm 0.31)$ \\
\hline \multicolumn{5}{|l|}{ Urinary Oxypurines } \\
\hline ( $\mu$ mole $/ \mathrm{mg}$ creatinine) & $0.14 \pm 0.07$ & $0.40 \pm 0.10$ & $0.95 \pm 0.08$ & $1.01 \pm 0.09$ \\
\hline
\end{tabular}


Table 4. Urinary Inosine Excretion During Exercise

\begin{tabular}{|c|c|c|}
\hline \multirow[b]{2}{*}{ Subject } & \multicolumn{2}{|c|}{$\begin{array}{c}\text { Urinary Inosine } \\
\text { ( } \mu \text { mole/mg creatinine) }\end{array}$} \\
\hline & Control & Exercise \\
\hline 1 & 3.9 & 96.0 \\
\hline 2 & 1.2 & 39.0 \\
\hline 3 & 1.6 & 1.4 \\
\hline 4 & 14.5 & 39.0 \\
\hline 5 & 2.2 & 9.0 \\
\hline Mean & 4.7 & 36.9 \\
\hline SEM & 2.5 & 16.6 \\
\hline
\end{tabular}

purine end-product. In extreme cases, abnormalities of uric acid metabolism have been implicated in the etiology of heat stress nephropathy ${ }^{18.19}$ and in the acute renal failure following prolonged epileptic seizures. ${ }^{20}$ In our study, the shorter duration of the progressive cycle ergometer test did not cause hyperuricemia, whereas the longer periods of exertion of a 5000 meter race and a 42 kilometer marathon were associated with uric acid increases of 1.5 and 1.7 $\mathrm{mg} / \mathrm{dl}$ respectively (Table 1 ). The failure to demonstrate any increase in plasma uric acid was probably related to exercise intensity or duration, as only the last 3 to 4 minutes of a progressive exercise test are at high intensities. The importance of exercise intensity is confirmed by more recent work from this laboratory in which 20 minutes of exercise at $70 \% \mathrm{VO}_{2}$ max consistently elevated plasma uric acid, whereas 20 minutes at $35 \% \mathrm{VO}_{2}$ max did not (Sutton, J.R., 1979, unpublished).

Elevations of the serum uric acid may result from a decreased renal excretion of uric acid, an increased synthesis of uric acid, or a combination of these two factors. Decreased renal clearance of uric acid during the period of vigorous exercise has been demonstrated by Nichols et al. ${ }^{6}$

\begin{tabular}{|c|c|c|}
\hline \multicolumn{3}{|c|}{ Nucleotides in 8 Subjects } \\
\hline & Control & Exercise \\
\hline & \multicolumn{2}{|c|}{ ( $\mu$ mole/g wet weight) } \\
\hline ATP & $5.17 \pm 0.7$ & $2.91 \pm 0.5 \dagger$ \\
\hline ADP & $0.85 \pm 0.1$ & $1.29 \pm 0.1 \ddagger$ \\
\hline AMP & $0.12 \pm 0.03$ & $0.15 \pm 0.03^{*}$ \\
\hline \multicolumn{3}{|l|}{ Total Adenine } \\
\hline Nucleotides & $6.14 \pm 0.8$ & $4.35 \pm 0.6 \dagger$ \\
\hline
\end{tabular}

Significance of $t$ test: "not significant; $\dagger \rho<0.001$ : $\nmid \rho<$ 0.01 . (Mean \pm 1 SEM) and a modest, but not significant, diminution of uric acid excretion was observed during the cycle ergometer test (Table 3). The factors that may account for this decrease of uric acid clearance include hypohydration, ${ }^{21}$ contracted extracellular volume, ${ }^{22}$ increased formation of angioten$\sin ,{ }^{23}$ and hyperlacticacidemia. ${ }^{24}$ However, not all previous observations can be explained by decreased urate excretion. Although hyperlacticacidemia is known to decrease the renal clearance of uric acid, hyperuricemia is not produced during short intervals ${ }^{25}$ and was not evident following the cycle ergometer study (Table 1). Fox et al. ${ }^{25}$ infused sodium lactate in large quantities over a two-hour period and found a markedly diminished fractional clearance of uric acid without any change in the serum uric acid. Hyperuricemia and hyperlacticacidemia had been obscrved immediately after severe exercise, but hyperuricemia alone persisted after 12 hours. ${ }^{18}$ Furthermore, uric acid was elevated out of proportion to blood urea following prolonged epileptic seizures. ${ }^{20}$ Thus, not all previous observations can be appropriately explained by decreased urate excretion.

There is direct evidence to support the possibility that increased uric acid synthesis accompanies exercise. During periods of vigorous military training, both the serum and urinary uric acid were observed to increase. ${ }^{18,26}$ An elevation of urinary oxypurines, mainly hypoxanthine, has been found in subjects exercising until exhaustion. ${ }^{10}$ The maximum progressive exercise test on a cycle ergometer did not cause hyperuricemia in spite of hyperlacticacidemia, but resulted in an elevation of plasma oxypurines, and urinary oxypurines and inosine. The increase of these precursors of uric acid in the plasma and urine of exercising subjects suggests an activation of the purine catabolic pathways leading to uric acid. ${ }^{27}$

Exercising human skeletal muscle has decreased ATP and creatine phosphate concentrations. ${ }^{16.28}$ The degree of high energy phosphate depletion appears to be related to the amount and duration of the power output. The maximum decrease described for ATP with exhaustion has been to $60 \%$ of the control values, while significant depletions to $81 \%$ of controls were found at $1200 \mathrm{kpm} / \mathrm{min}^{16}{ }^{16}$ In our study, muscle ATP concentrations decreased to $56 \%$ of the control values with the maximum power of 1600 
$\mathrm{kpm} / \mathrm{min}$. Exercise in humans has also been accompanied by elevated peripheral venous uric acid and oxypurines, and urinary oxypurines and inosine (Table 1) ${ }^{1,4,5,7,9}$

Although our exercise studies do not prove the source of these increased catabolic intermediates in the peripheral venous blood and urine, stoichiometric considerations suggest that exercising muscle may be the source of the purine intermediates. During the cycle ergometer test, plasma oxypurines increased by $65 \mu M$ (18 to 83 $\mu M$ ) on allopurinol therapy or by $31 \mu M$ (19 to $50 \mu M$ ) without allopurinol. If it is assumed that oxypurines can be distributed in total body water, then this could represent $2600 \mu$ moles of oxypurines with allopurinol therapy or 1240 $\mu$ moles without allopurinol at one point in time. However, these calculations may only represent a fraction of the total oxypurine turnover. It is more likely that there is active production of hypoxanthine and reutilization of this compound to form IMP by hypoxanthine-guanine phosphoribosyltransferase. The reutilization of hypoxanthine is highly efficient, since in the absence of hypoxanthine-guanine phosphoribosyltransferase, there is a massive increase in purine excretion, which results in part from an inability to reutilize hypoxanthine. ${ }^{2}$ The efficiency of reutilization is reflected in part by the urinary excretion of only 100 to $200 \mu$ moles of oxypurine at the most during cycle ergometry. The decrease of muscle adenine nucleotides observed can more than account for this quantity of oxypurine formation. In a $70-\mathrm{kg}$ man exercising $30 \mathrm{~kg}$ of muscle, ATP decreased by $2.3 \mu \mathrm{mol} / \mathrm{g}$ for a total $69,000 \mu \mathrm{mol}$ reduction of ATP. Although the liver could generate substantial quantities of oxypurines from adenine nucleotides, it seems less likely to account for the changes observed. Since total adenine nucleotide concentration is $2.5 \mu \mathrm{mol} / \mathrm{g}$ of liver, ${ }^{17}$ a $50 \%$ decrease of adenine nucleotide concentration would only generate about $1900 \mu$ moles of oxypurine (assuming a liver weight of $1500 \mathrm{~g}$ ).

There is a known relationship between decreased intracellular ATP concentrations, increased AMP concentrations, and activation of purine nucleotide catabolism. ATP inhibits the activity of 5 -nucleotidase and alkaline phosphatase and the $\mathrm{k}_{\mathrm{m}}$ for AMP is in the range of known physiologic concentrations. ${ }^{29}$ The diminution of intracellular ATP levels and concomitant increased concentrations of AMP and possible IMP could lead to the activation of the nucleotide dephosphorylation reaction and accelerate purine nucleotide degradation to the catabolic

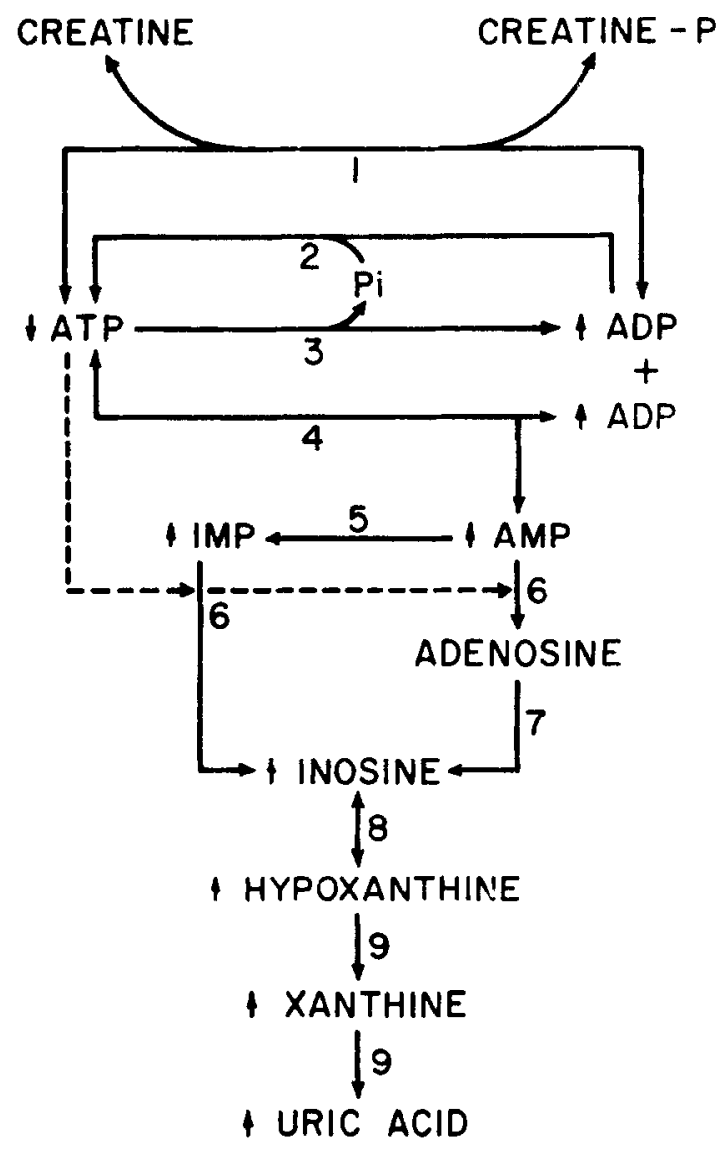

Fig. 1 Postulated effects of exercise on human purine ribonucleotide catabolism. In muscle tissue. ATP may be converted to ADP by myosin ATPase (3) during exercise. The ADP generated may be converted to ATP by creatinephosphokinase (1), the mitochondrial electron transport system (2), glycolysis (2), and by adenylate kinase (4). As ATP decreases, there is a buildup of AMP and IMP, with the latter being formed by adenylate deaminase (5). The increase of IMP and AMP and the decrease of ATP activate dephosphorylation by 5 -phosphomonoesterases (6). There ensues a cascade of nucleotide degradation to purine catabolic intermediates. AMP or IMP are dephosphorylated by nonspecific phosphatase or 5'-nucleotidase (6). Adenosine deaminase (7) degrades adenosine to inosine. Inosine is degraded to hypoxanthine by purine nucleoside phosphorylase (8). Hypoxanthine is converted to xanthine and xanthine is converted to uric acid by xanthine oxidase (9), a reaction which allopurinol inhibits. Oxypurines refer to hypoxanthine and xanthine together. The dotted line indicates inhibition of (6) by ATP. The arrows show changes related to muscular exercise with increase ( $\uparrow$ ) and decrease ( $(1)$. The numbers above in the text indicate enzyme reactions. 
intermediates. ${ }^{27}$ The elevation of plasma creatine phosphokinase following exercise would also support muscle as the site of origin of the purine nucleotides.

An alternative mechanism to account for the exercise-induced increase of purine degradation products is the activation of purine biosynthesis de novo. Although the acute diminution of muscle nucleotides would not support this as a primary mechanism, it is likely that such an increase of purine biosynthesis could occur in response to the diminution of intracellular nucleotides. ${ }^{30}$ This secondary mechanism has been proposed to explain the elevation of purine synthesis accompanying fructose-induced hyperuricemia. ${ }^{31-34}$

Thus, studies of purine metabolism in vigorous muscular exercise suggest a complicated regulatory mechanism dependent upon changes in the intracellular nucleotide environment. Physiologic alteration of this system, initiated by decreases of ATP concentrations, could be a factor leading to the nucleotide catabolism observed (Fig. 1).

\section{REFERENCES}

1. Kelley WN: Effects of drugs on uric acid in man. Ann Rev Pharmacol 15:327-350, 1975

2. Edwards NL, Recker D. Fox IH: Overproduction of uric acid in hypoxanthine-guanine phosphoribosyltransferase deficiency: Contribution by impaired purine salvage. J Clin Invest 63:922-930, 1979

3. Wyngaarden JB: Metabolic defects of primary hyperuricemia and gout. Am J Med 56:651-664. 1974

4. Cathcart EP, Kennaway EL, Leathes JB: On the origin of endogenous uric acid. Quart J Med 1:416-447, 19071908

5. Levine SA, Gordon B, Derick CL: Some changes in the chemical constituents of the blood following a marathon race. JA MA 82:1778-1779, 1924

6. Nichols J, Miller AT, Hiatt EP: Influence of muscular exercise on uric acid excretion in man. J Appl Physiol 3:501-507, 1950-1951

7. Rakestraw NW: Chemical factors in fatigue. 1. The effect of muscular exercise upon certain blood constituents. $\mathrm{J}$ Biol Chem 47:565-591, 1921

8. Saiki AK, Olmanson G, Talbert GA: Simultaneous study of the blood, also gastric and other manifestations resulting from sweating. Am J Physiol 100:329-330, 1932

9. Sutton J, Coleman MJ, Millar AP, et al: The medical problems of mass participation in athletic competition: The "City-to-Surf" race. Med J Aust 2:127-133, 1972

10. Nasrallah S, Al-Khalidi V: Nature of purines excreted in urine during muscular exercise. J Appl Physiol 19:246-248, 1964

11. Sutton JR, Jones NL: Exercise testing in health and disease. Can Family Physician 20:66 69, 1974

12. Bergstrom J: Muscle electrolytes in man determined by neuron activation analysis on needle biopsy specimens. A study on normal subjects, kidney patients and patients with chronic diarrhoea. Scand J Clin Lab Invest 14 (suppl 68), 1962

13. Yu TF, Gutman AB: Quantitative analysis of uric acid on blood and urine: Methods and interpretation. Bull Rheumat Dis (suppl 7):517-519, 1957

14. Brod J, Sirota JH: The renal clearance of endogenous creatinine in man. J Clin Invest 27:645-654, 1948

15. Klinenberg JR, Goldfinger S, Bradley KH, et al: An enzymatic spectrophotometric method for the determination of xanthine and hypoxanthine. Clin Chem 13:834-846, 1967

16. Hultman E, Bergstrom J, Anderson NM: Breakdown and resynthesis of phosphorylcreatine and adenosine triphosphate in connection with muscular work in man. Scand $J$ Clin Lab Invest 19:56-66, 1967

17. Toews CJ, Lowy C, Ruderman NB: The regulation of gluconeogenesis. J Biol Chem 245:818-824, 1970

18. Knochel JP, Dotin LN. Hamburger RJ: Heat stress. exercise and muscle injury: Effects on urate metabolism and renal function. Ann Intern Med 81:321-328, 1974

19. Schrier RW, Hano J, Keller HI, et al: Renal, metabolic and circulatory responses to heat and exercise. Ann Intern Med 73:213-223, 1970

20. Warren DJ, Leitch AG, Leggett RJE: Hyperuricemic acute renal failure after epileptic seizures. Lancet 2:385 387,1975

21. Magazanik A, Shapiro Y, Meytes D, Meytes I: Enzyme blood levels and water balance during a marathon race. J Appl Physiol 36:214-217, 1974

22. Steele TH: Evidence for altered renal urate reabsorption during changes in volume of the extracellular fluid. J Lab Clin Med 74:288-299, 1969

23. Ferris TF, Gordon P: Effect of angiotensins and norepinephrinc upon urate clcarance in man. Am J Med 44:359-365, 1968

24. Quick AJ: The effect of exercise on excretion of uric acid. J Biol Chem 110:107-112, 1935

25. Fox IH, Halperin ML, Goldstein MB, et al: Renal excretion of uric acid during prolonged fasting. Metabolism 25:551--559, 1976

26. Zir LM, Mchugh WB, Rahe RJ, et al. Remal excretion of uric acid. Alterations during stressful underwater demolition team training. Arch Int Med 132:808-815, 1973

27. Fox IH: Human ribonucleotide catabolism: Clinical and biochemical significance. Nutr Metab 16:65- 78. 1974

28. Karlsson J: Lactate and phosphagen concentrations in working muscles of man. Acta Physiol Scand (suppl 358). 1971

29. Fox IH, Marchant PJ: Purine catabolism in man: 
Inhibition of $5^{\prime}$-phosphomonoesterase activities from placental microsomes. Can J Biochem 54:1055-1060, 1976

30. Tulley ER, Sheehan TG: Purine metabolism in rat skeletal muscle. J Clin Chem Clin Biochem 17:445-446, 1979

31. Emmerson BT: Effect of oral fructose on urate production. Ann Rheum Dis 33:276-280, 1974

32. Fox IH, Kelley WN: Studies on the mechanism of fructose-induced hyperuricemia in man. Metabolism 21:713-721, 1972

33. Narins RG, Weisberg JS, Meyers AR: Effect of carbohydrates on uric acid metabolism. Metabolism 23:455465,1974

34. Raivio KO, Becker MA, Meyer LA, et al: Stimulation of human purine synthesis de novo by fructose infusion. Mctabolism 24:861-869, 1975 